\title{
Impact of weather parameters on cotton productivity at Surat (Gujarat), India
}

\author{
H. S. Thakare, P. K. Shrivastava* and Kirti Bardhan \\ Department of Natural Resource Management, ASPEE College of Horticulture and Forestry, Navsari Agricultural \\ University, Navsari - 396450 (Gujarat), INDIA \\ *Corresponding author. E-mail: pkshrivastavanvs@yahoo.co.in
}

Received: July 15, 2014; Revised received: September 10, 2014; Accepted: November 05, 2014

\begin{abstract}
Global warming is casting its shadow in the form of climatic changes that is affecting the local weather conditions which has its bearing on crop production and water availability, the basic necessities for survival of life on the planet. In the present study, an attempt was made to investigate the cause of poor production of cotton in 2011-12 in Surat, Gujarat as compared to 2012-13 and 2013-14. Weather data since 2000 was analyzed and compared with the data of 2011-12 and comparison was made to find the abnormality in cotton crop productivity. It was found that during 2011-12, there was delayed monsoon, as well as during squaring and flowering stage (i.e. in August 2011) there was high rainfall $(595.6 \mathrm{~mm})$, maximum and minimum temperatures were above normal, during development (June-August) and flowering stage of crop (October-December) which disturbed the crop physiology indirectly affecting the yield of cotton. The combined effect of rainfall and temperature was on relative humidity that created conducive atmosphere for insect and pest attacks on crops. Due to changes in temperature and relative humidity, evaporative water demands would have further aggravated the watering needs of crop. The study concludes that erratic monsoon or delayed monsoon hampers crop physiology ultimately yield due to erratic weather conditions. Further, such changes in cotton growing areas could form the basis of planning and decisions on pricing, crop insurance, export and import policies of cotton crop.
\end{abstract}

Keywords: Cotton, Rainfall, Relative humidity, Temperature

\section{INTRODUCTION}

Cotton is one of the most important commercial crops popularly known as the "White Gold", belonging to the genus Gossypium under tribe Gossypieae of Malvaceae family. It is the most precious gift of nature to the mankind to cloth the people all over the world. Cotton accounts more than $70 \%$ of the raw fibre used by the world textile industry and handlooms hence it is also called "King of fibres" (James 2006). Cotton contributes not only fibre to the textile industry but also edible oil which plays an important role in meeting the ever increasing demand of edible oil in the country. Edible oil extracted from the cotton seed is estimated to the 5 lakh tonnes along with 30 lakh tonnes cake. In India, all the four cultivated cotton species viz., Gossypium arboreum, G. herbaceum, G. hirsutum and $G$. barbadense are grown on commercial scale (Singh and Kairon, 2008). Cotton is a perennial with an indeterminate growth habit. Wild ancestors of cotton are found in arid regions often with high temperatures and are naturally adapted to surviving long periods of dry weather. Modern cultivars have inherited these attributes, making the cotton crop well adapted to intermittent water supply that occurs with rain-fed and irrigated production. Compared with other field crops, however, its growth and development is complex (Bange, 2007). Vegetative and reproductive growth occur simultaneously making interpretation of the crop's response to climate and management difficult. Climate change impacts on cotton growth and development that influence yield and fibre quality will most likely be the result of the net effects of increases in $\mathrm{CO}_{2}$ concentration, reduced water availability and increased atmospheric evaporative demand as a result of lower rainfall and relative humidity and increases in temperature (Bange, 2007).

The cotton production in the country is highly variable due to its wide adaptability in different climate regions. In the present scenario of climate change led global warming; there is great challenge of sustainable cotton production. Different weather parameters (i.e. temperature, rainfall, humidity etc.) affect phenology, development and yield of cotton crop. Temperature is one of the important weather parameter which affects growth, development and yield of crop. Ghosh et al. (2014) studied the effect of temperature on cotton and reported that maximum temperature was positively correlated with pest incidence and minimum temperature was negatively correlated. Reddy et al. (1999) also observed that high temperatures produce 
bud shedding in cotton and they further reported that temperature regimes alter boll development, boll size and the maturity period both decreased as the temperature increased. Boll growth decreases significantly and fruit sheds 3-5 days after blossoming at temperatures above $32{ }^{\circ} \mathrm{C}$ (ICAC, 2007). Rainfall is another weather parameter, which also affects the growth and development of cotton plant. Srinivasan (1973) studied about the influences of rainfall on the yield of cotton in Madhya Pradesh, whereas, Gupta and Pandey (1991) studied the same for Surat and reported negative effect of maximum and minimum rainfall on cotton crop. Gwimbi and Mundoga (2010) measured impact of climate change for the entire growing season of cotton and found that cotton production levels declined as precipitation decreased and temperature increased. However, the effect of climate change on cotton yields may not only depend on precipitation, but the precipitation occurring during specific growth stages (germination, fruiting, and maturity). Only few studies (Williford et al., 1995; Parvin et al., 2005) have focused on the relationship between the effects of early- and late-season precipitation on cotton yields. Dubey et al. (1995) also studied the estimation of cotton yield based on weather parameters of Maharashtra. Relative humidity is another weather parameter which also directly and indirectly affects yield of crop. Ramamurthy et al. (2000) and Singh et al. (2009) reported that the relative humidity was found to be the vital weather parameters which contributed to the infestation of sucking pests. Exports of the crop from developing countries reached US\$ 2.8 billion in 2009-2010, providing incomes to millions of farmers. It is therefore important to understand the scope for cotton farmers to adapt to the changing climate and how cotton production can have a reduced emissions profile (ITC, 2011). Keeping in view, the present investigation was conducted to study the impact of weather parameters on cotton productivity at Surat (Gujarat), India.

\section{MATERIALS AND METHODS}

One of the major cotton growing areas in Gujarat is Surat which has been selected for the present study. Surat is situated in Southern Gujarat at a cross point of $20^{\circ}-12$ ' $\mathrm{N}$ latitude and $72^{0}-52^{\prime}$ longitude at elevation of 11.34 meters above the mean sea level and is about 18 Kilometres away from the Arabian seashore. The climate of South Gujarat is typically tropical, characterized by fairly hot summer, moderately cool winter and more humid and warm monsoon with heavy rainfall. In general, monsoon commences from the second fortnight of June and ceases in the second fortnight of September. Pre monsoon rains in the first week of June and post monsoon rains in the months of October-November are not common. The rain is received mainly from the South West monsoon concentrating in the months of July and August. The average annual precipitation in Surat is $1188 \mathrm{~mm}$ (Average of ten years). The winter sets in the end of October and lasts up to February. The temperature starts decreasing in the middle of November. December and January are the coldest months of season. The summer season commences during the middle of February and prolongs up to first week of June. April and May are the hottest months of summer. Last 13 years (2001-2013) mean meteorological data on maximum and minimum temperature, maximum and minimum relative humidity, rainfall of Surat were collected from Meteorological laboratory of Navsari Agricultural University and analyzed. Cotton yield of last three years was collected from Main Cotton Research Station, Surat, Gujarat; it was observed that during 2011-12, yield was below average compared to 2012-13 and 2013-14. Thus, to quantify the relationship between weather parameters and yield of cotton, analysis of 13 years average as compared to the data of 2011 was done.

\section{RESULTS AND DISCUSSION}

Average data of seed cotton yield of three years (Fig.1) shows that there was decrease in average yield in 2011 -12 (1991 kg/ha) as compared to 2012-13 (2254 kg/ha) and 2013-14 (2123 kg/ha), while adopting similar cultivation practices.

The data on total rainfall during 2011-12 and average rainfall during 13 years indicates that, there was very low rainfall during 2011-12 (31.0 $\mathrm{mm})$ as compared to 13 years average rainfall $(285.5 \mathrm{~mm})$, during main sowing period of cotton i.e. June-July which affected the sowing time of crop (delayed in sowing period) which ultimately affected growth, as well as enhanced irrigation needs ultimately affected the crop physiology of cotton. Delayed monsoon or failure of monsoon could only be tackled, if, cotton growers have assured irrigation facility and are adopting drip irrigation along with other water management practices to improve water use efficiencies. Water stress in cotton restricts both vegetative and fruit growth. Cotton's response to stress varies on the stage of growth, the degree of stress and length of stress. Research in India has shown that to prevent yield reductions, cotton crop generally requires enough water to allow $700 \mathrm{~mm}$ of evapo-transpiration (transpiration plus soil evaporation).

In the study, fig 2 indicates that during squaring and flower development (i.e. in August 2011) there was high rainfall $(595.6 \mathrm{~mm})$, which disturbed the crop physiology that indirectly affected the yield of cotton. Bhan and Kharbanda (2004) reported that as cotton is an indeterminate plant, higher rainfall and moderate temperatures during vegetative and early reproductive stages lead to excessive growth of crop and makes the crop more succulent. The excessive growth of the crop creates a favourable microclimate for rapid multiplication of the pest and also increasing the 


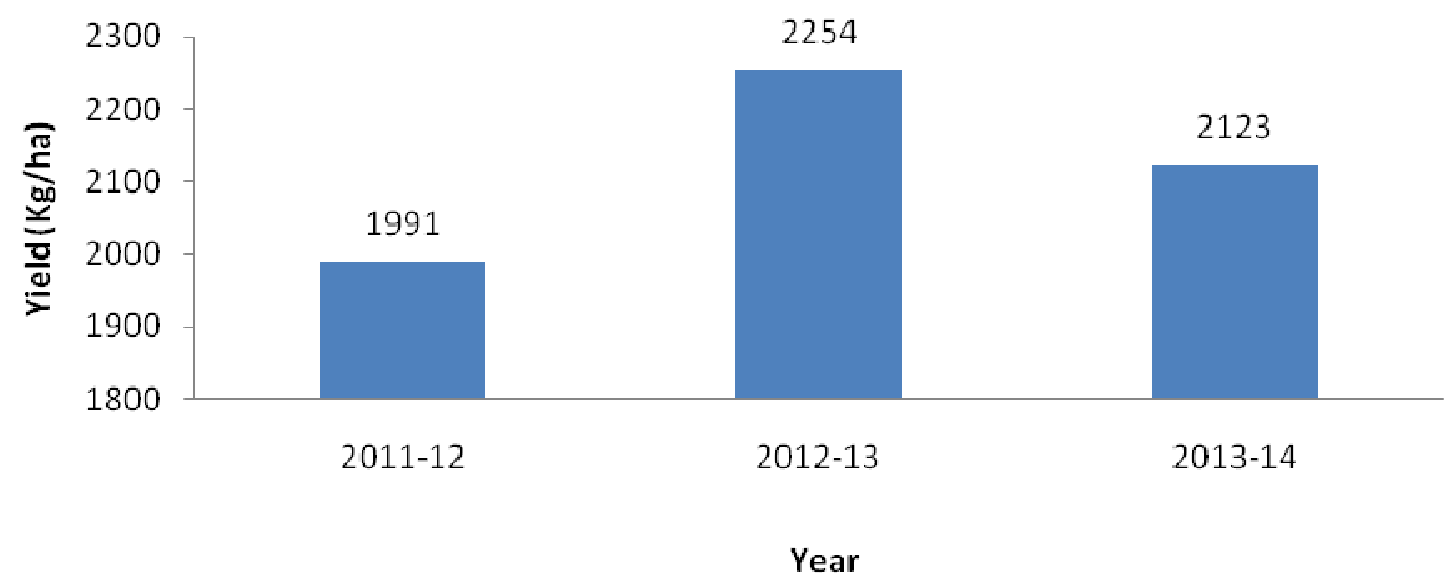

Fig. 1. Seed cotton yield ( $\mathrm{Kg} / \mathrm{ha})$.

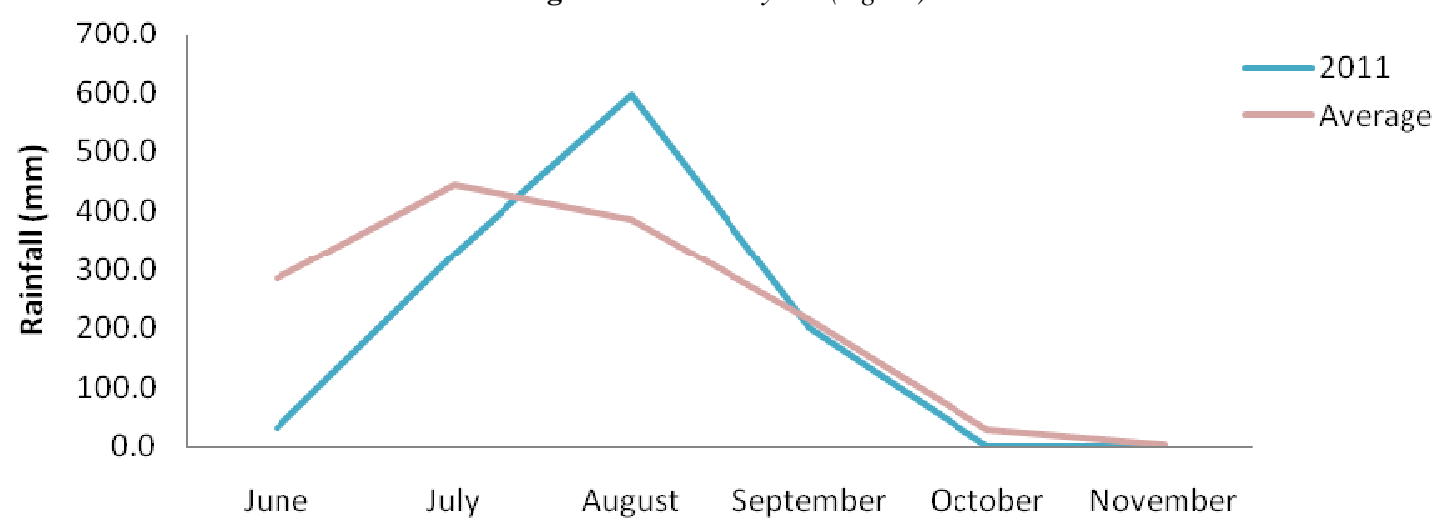

Fig. 2. Average Rainfall of 13 year Vs Rainfall of 2011.

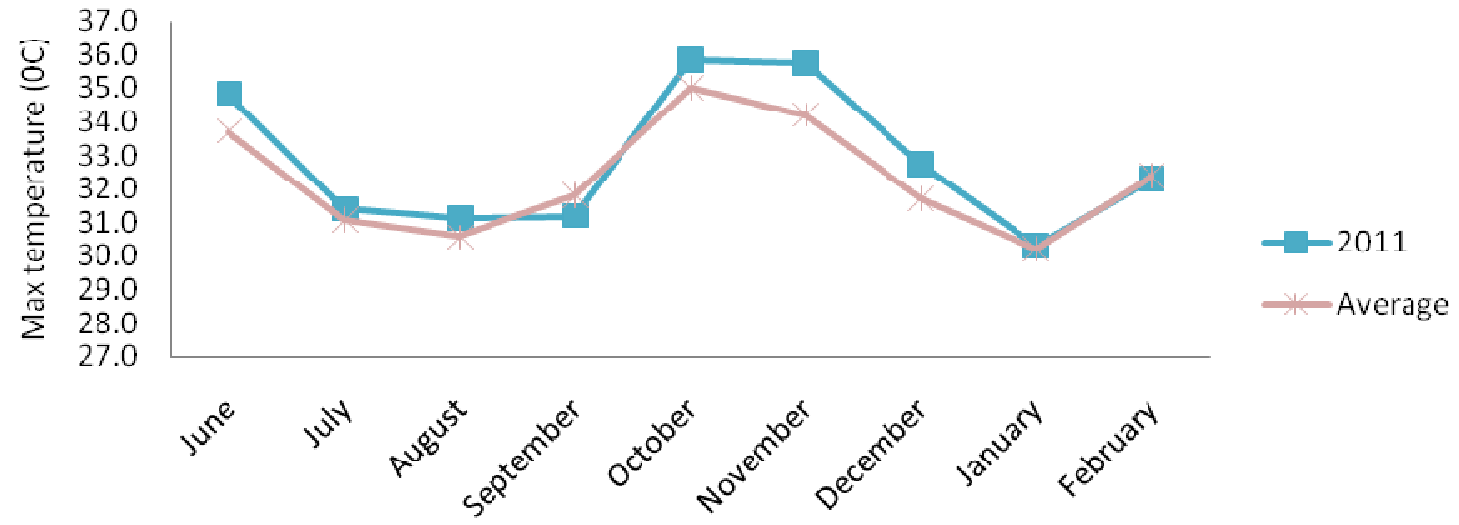

Fig. 3. Average maximum temperature (13 year) Vs Maximum temperature in 2011.

succulence of the crop making it more susceptible to infestation. Santharam (1981) and Dubey et al. (1995) reported that rainfall during flowering, boll opening and harvesting was harmful in cotton.

Temperature has two main influences on cotton growth and development. Firstly it determines the rates of morphological development and crop growth (e.g. node development, rate of fruit production, photosynthesis and respiration). Secondly, it also helps to determine the start and end of a growing season (Bange, 2007).

The data presented in fig. 3 depict that maximum temperature was above average during 2011, especially during development (June-August) and flowering stage of crop (October-December) as compared to 13 years average maximum temperature, which affects the growth and phenology of crop and ultimately the yield of crop. Bange (2007) also reports that fibre length gets affected by sustained periods of high temperatures as the time required for fibre elongation is reduced, not allowing fibre length to reach its genetic potential. Fibre length is reduced as temperatures increases beyond $32^{\circ} \mathrm{C}$.

Increases in temperature also reduced the interval between flowering and boll opening, thus shortening the time to maturity that causes yield reduction. This 
may increase final micronaire by limiting the number of late set bolls that can have lower micronaire. Cotton buyers and textile manufacturers prefer a micronaire range of 3.8 to 4.5 , and a fibre length of 20 to $28 \mathrm{~cm}$. Thicker or thinner fibres cause problems in both spinning and uniform dying of yarn. Buyers discount the value of both high and low micronaire cotton. In addition to reductions in assimilates available for growth, heat stress also directly damage cotton plant tissues affecting fibre quality parameters. Sankaranarayanan et al. (2010) reported that 40 and $50 \%$ less biomass is anticipated in cotton (Gossypium sp.) at $20 / 10{ }^{\circ} \mathrm{C}$ and $40 / 30{ }^{\circ} \mathrm{C}$, respectively, with optimum temperature of $30 / 20{ }^{\circ} \mathrm{C}$. Bhargawa and Bharadwaj (1969) reported that high temperature reduced the number of flowers in cotton.

The data on minimum temperature presented in fig. 4 depict that during flowering period of crop (OctoberDecember) the minimum temperature was found to increase in 2011-12 as compared to 13 year average temperature.

Bange (2007) reports that warm nights (above $25^{\circ} \mathrm{C}$ ) results in high leaf temperature causing higher respiration and consuming stored assimilates, while excessively high temperatures (greater than $35^{\circ} \mathrm{C}$ ) during the day can reduce photosynthesis.
Maintenance respiration approximately doubles for every $10^{\circ} \mathrm{C}$ rise in temperature. Both situations reduce the amount of assimilates available for growth, and in turn reduce yield by causing increase in square and boll shedding and reducing seed number per boll. Loss of fruit may cause excessive vegetative growth following the period of heat stress. Further, he also noted that during flowering, high temperatures reduce the viability of the pollen. This reduces boll size and reduces yield. The result is small bolls with uneven seed numbers between the locules caused by poor pollination/seed set particularly in one lock. At night the plant loses the ability to cool evaporative (no transpiration), so tissue temperatures approach air temperature. During the day very high relative humidity (which restricts evaporative cooling) in combination with clear skies can also increase tissue temperature to approach or exceed air temperature.

Changes in temperature directly or indirectly affected maximum and minimum relative humidity in 2011-12, that is reflected by variance in maximum and minimum relative humidity (Figs. 5, 6). Further, figure also depict that the maximum and minimum relative humidity in 2011-12 was minimum as compared to 13 year average data except in month of October.

Lower relative humidity caused by climate change will

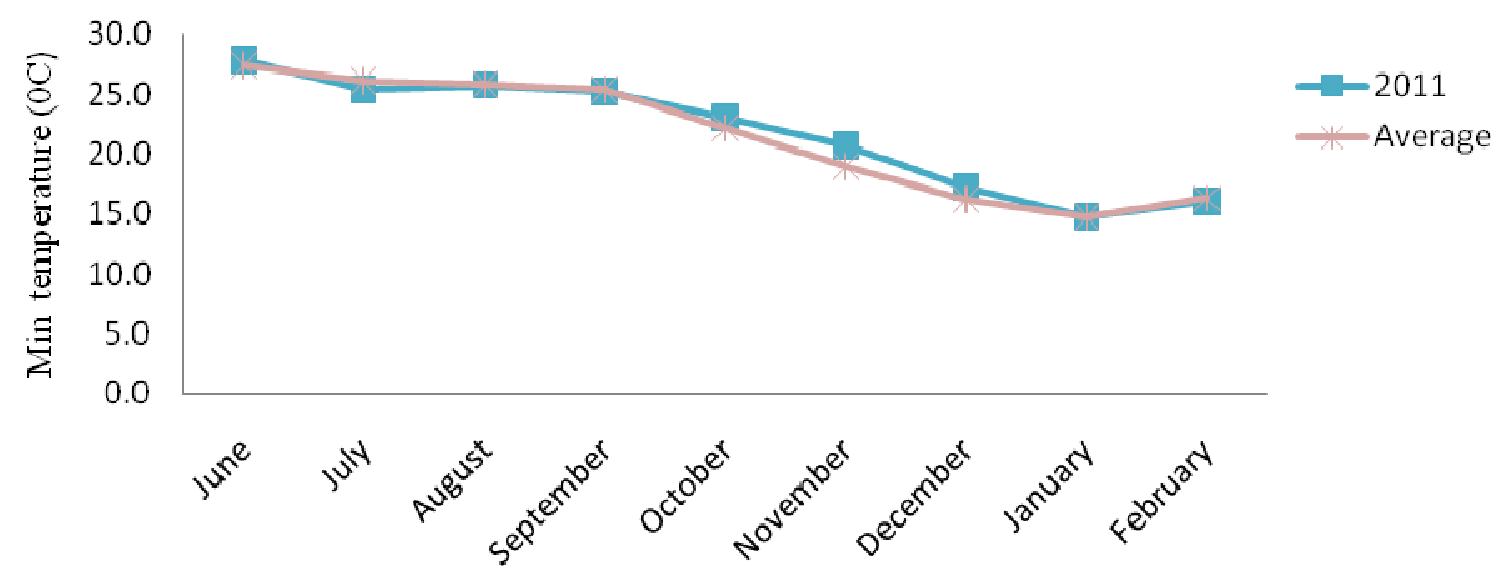

Fig. 4. Average minimum temperature (13 years) vs minimum temperature in 2011.

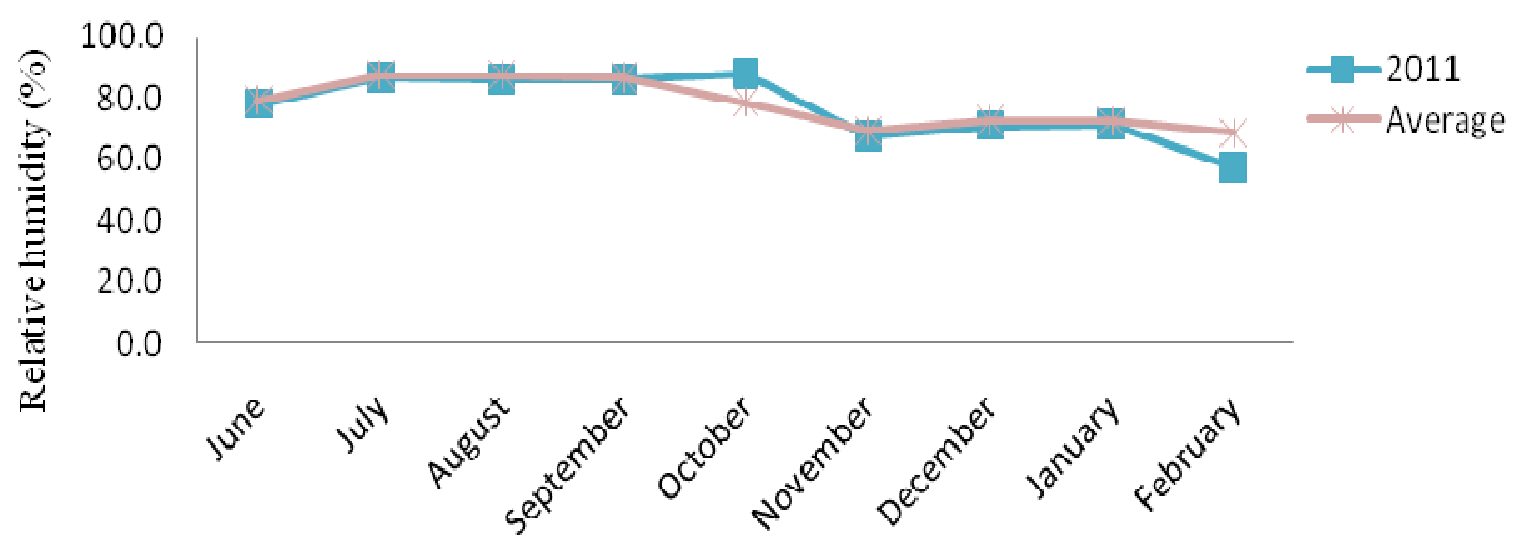

Fig. 5. Average (13 years) maximum relative humidity vs maximum relative humidity in 2011 . 


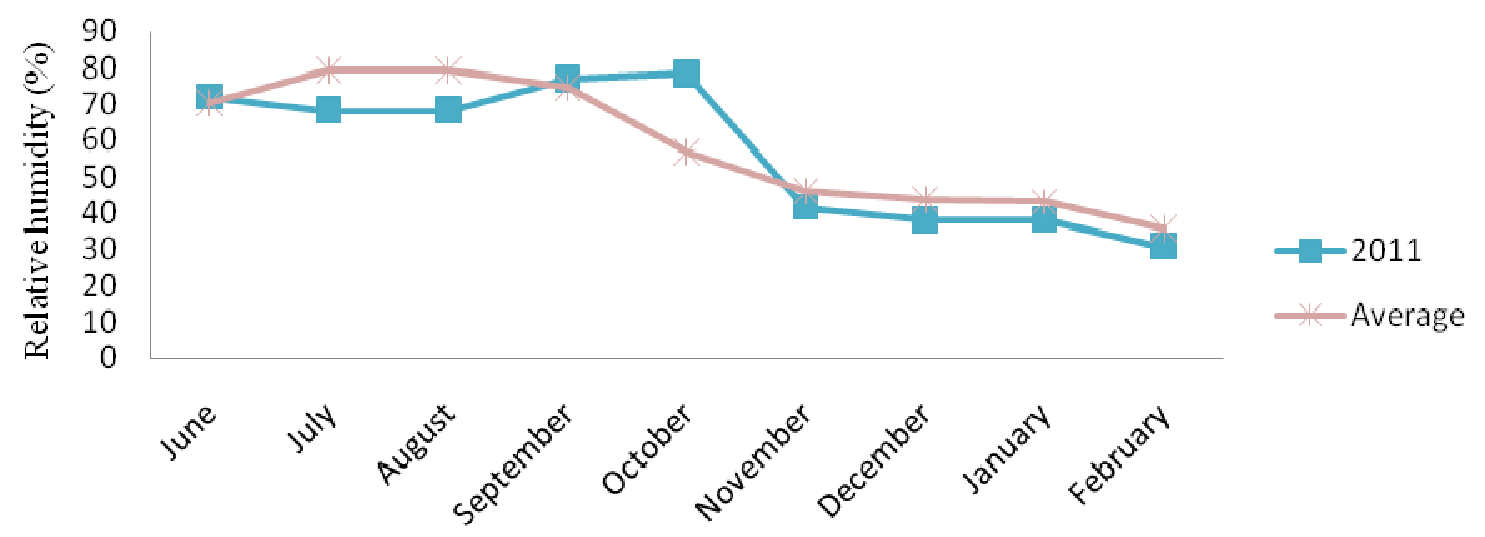

Fig. 6. Average (13 yea s) minimum relative humidity vs mimimum relative humidity of 2011.

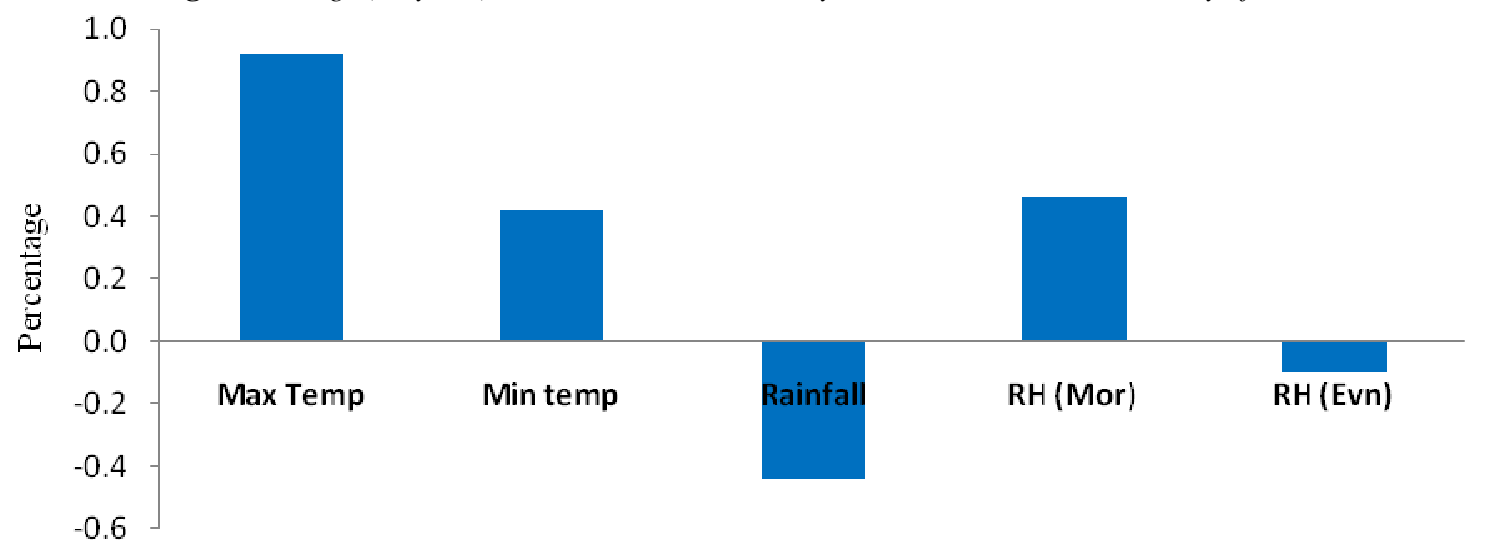

Fig.7. Correlation of wether parameters with cotton yield .

increase evaporative demand by the atmosphere surrounding crops. Changes in evaporative demand will influence the amount of evapo-transpiration affecting both transpiration and soil evaporation (Bange, 2007). Singh et al. (2009) and Ramamurthy et al. (2000) recorded positive correlation between relative humidity and infestation of sucking pests in cotton.

Transpiration is used by crops to regulate temperature of their canopies. Higher evaporative demand in well watered crops has the potential to increase transpiration and soil evaporation, lowering water use efficiency. In situations where water is limited and there is high evaporative demand, crops will struggle to transpire enough to keep the canopies cool. Leaf temperatures are then increased to a point where photosynthesis and growth are impaired.

The data presented in fig. 7 shows that among the different weather parameters, rainfall (-0.4) and minimum relative humidity $(-0.1)$ is negatively correlated with yield, whereas max and min temperature and relative humidity (max) was positively correlated. Deshmukh and Lunge (2012) also noted positive correlation between temperature and cotton yield. Chattopadhyay et al. (2008) reported that minimum temperature favoured the yield of cotton, whereas, Shaha and Banerjee (1975) observed that normal relative humidity was beneficial to the cotton grown in Coimbatore.
Further, it can be deduced that maximum and minimum temperature affects crop yield followed by maximum relative humidity, relative humidity could also be causing insect pest attacks ultimately affecting crop production. Singh et al. (2009) and Ramamurthy et al. (2000) also reported similar results; they recorded positive correlation between relative humidity and infestation of sucking pests in cotton. Negative correlation of rainfall with yield could be attributed to the fact that, rains indirectly govern all the other weather parameters during the season as well as affecting germination.

\section{Conclusion}

The study showed that cotton crop yield during 2011-12 is directly affected due to weather parameters of the region. It also shows that rainfall is the main component which governs the other weather parameters during rainy season. Onset of monsoon affected germination and initial growth, whereas, abnormal temperatures affected crop physiology and quality of produce. Combined effect of rainfall and temperature was on relative humidity that created conducive atmosphere for insect and pest attacks on crops. Therefore, it is concluded that erratic monsoon or delayed monsoon hampers crop physiology and yield due to changes in other weather parameters. Further, such changes in cotton growing areas could be 
the basis for planning the decisions on crop insurance, export and import policies of cotton crop.

\section{REFERENCES}

Bange, M. (2007). Effects of climate change on cotton growth and development. The Australian Cotton Grower, 40-45.

Bhan, S.C. and Kharbanda, K.L. (2004). Effect of rainfall and temperature distribution on incidence of American bollworm on cotton in Haryana. Mausam, 55 (3): 481484.

Bhargawa, S.C. and Bharadwaj, S.N. (1969). Effect of photoperiod and sowing time of flowering of cotton $\mathrm{H}-$ 14. Indian J. Agric. Sci., 39: 553-556.

Chattopadhyay, N., Samual, R.P. and Banerjee, S.K. (2008). Effect of weather on growth and yield of cotton grown in the dry farming tract of peninsular India. Mausam, 59 (3): 339-346.

Deshmukh, D.T. and Lunge, H.S. (2012). Impact of global warming on rainfall and cotton lint with vulnerability profiles of five districts in Vidarbha, India. International Journal of Scientific \& Technology Research, 1 (11): 77-85.

Dubey, R.C., Choudhary, A. and Kale, J.D. (1995). The estimation of cotton yield based on weather parameters on Maharashtra. Mausum, 46: 275-278.

Ghosh, K., Rajavel, M., Samui, R.P., Singh, G.P. and Karmakar, C. (2014). Forewarning incidence of American boll worm (Heliothis armigera $\mathrm{H}$.) of cotton at Akola in Vidarbha region of Maharashtra. Mausam, 65 (1): 73-82.

Gupta, B.R.D. and Pandey, V. (1991). Influences of weathers parameters and agroclimatic elements on cotton yield at Surat. Mausam, 42: 107-110.

Gwimbi, P. and Mundoga, T. (2010). Impact of climate change on cotton production under rainfed conditions: Case of Gokwe. Journal of Sustainable Development in Africa, 12 (8): 59-69.

ICAC (2007). (International Cotton Advisory Committee, United States of America) Global warming and cotton production - Part 1. In: ICAC Recorder, 25 (4): 12-16.
ITC (2011). Cotton and Climate Change: Impacts and options to mitigate and adapt. Geneva: xii, p 32. International Trade Centre (Technical paper).

James Henry Hammond (2006) Cotton is king, Speech by Senate of South Carolina before United States Senate, Teaching American History : 311-322

Parvin, D.W., Martin, S.W., Cooke, F. Jr. and Freeland, B.B. (2005). Economics and Marketing: Effect of harvest season rainfall on cotton yield. The Journal of Cotton Science, 9: 115-120.

Ramamurthy, M., Rajaram, V., Rajenderan, M. and Krishnadoss, D. (2000). Impact of weather parameters on cotton pests. J. Cotton Res. Dev., 14: 193-195.

Reddy, K.R., Davidonis, G.H., Johnson, A.S. and Vinyard, B.T. (1999). Temperature regime and carbon dioxide enrichment alter cotton boll development and fiber properties. Agron. J., 91:851-858.

Sankaranarayanan, K., Praharaj, C.S., Nalayini, P., Bandyopadhyay, K. and Gopalakrishnan, N. (2010). Climate change and its impact on cotton (Gossypium sp.). Indian Journal of Agricultural Sciences, 80 (7): 561-575.

Santharam, V. (1981). Cotton, Series No. 1, ICAR, New Delhi.

Shaha, S.K. and Banerjee, J.R. (1975). Influences of rainfall, humidity, sunshine, maximum and minimum temperature on yield of cotton at Coimbatore. Indian $J$. Met. Hydrol. \& Geophys., 26: 518-524.

Singh, P. and Kairon, M.S. (2008). Cotton varieties and Hybrids. CICR Technical bulletin No: 13. Central Institute for Cotton Research Nagpur. (www.cicr.org.in)

Singh, S.P., Sekhon, B.S., Brar, J.S., Dhaliwal, L.K. and Chahal, S.K. (2009). Effect of weather parameters and plant geometry on sucking pest dynamics in Bt and non Bt cotton. Journal of Agrometeorology, 11: 129-234.

Srinivasan, P.S. (1973). Influences of rainfall on the yield of cotton in Madya Pradesh. Indian J. Agric. Sci., 43: 854859.

Williford, J.R., Cooke, F.T., Caillouet, D.F. and Anthony, S. (1995). Effect of harvest timing on cotton yield and quality. In Proc. Beltwide Cotton Conf., San Antonio, TX. Natl. Cotton Counc. Am., Memphis, TN. (4-7 January 1995): pp. 633-635. 